\title{
Efeito da adubação na população de Corythaica cyathicollis em berinjela, em função do período de coleta
}

\author{
Sandra Regina da Silva Ventura \\ Acacio Geraldo de Carvalho \\ Fabiano Teixeira Pereira \\ Universidade Federal Rural do Rio de Janeiro \\ Caixa Postal 113899, CEP 2490-000, Maricá, Brasil \\ sandraventura1@yahoo.com.br
}

Submetido em 15/04/2007

Aceito para publicação em 27/09/2007

\section{Resumo}

Corythaica cyathycollis (Costa, 1864) (Hemiptera, Tingidae) é uma das principais pragas de Solanum melongena e causa sérios prejuízos para a cultura. Para se determinar o efeito da adubação nitrogenada e potássica sobre a ocorrência de $C$. cyathicollis em berinjela foi desenvolvido o presente estudo. Os tratamentos constituíram de 3 níveis de nitrogênio $(0,60$ e 120kg/ha) e três níveis de potássio $(0,30$ e $60 \mathrm{~kg} / \mathrm{ha})$, avaliados em 3 períodos do dia, realizadas em amostragens semanais. Os resultados indicaram diferença estatística significativa no número de insetos da espécie C. cyathicollis, entre as plantas que foram adubadas com $120 \mathrm{~kg}$ de $\mathrm{N} / \mathrm{ha}(224,42)$ e $60 \mathrm{~kg}$ de N/ha $(197,50)$, no período do tarde.

Unitermos: Tingidae, período do dia, nitrogênio, potássio

\section{Abstract}

Effect of the fertilization on the population of Corythaica cyathicollis in eggplants in function of the collection period. Corythaica cyathicollis (Costa, 1864) is one of the main pests on Solanum melongena and it is known to cause serious damage to the culture. To determine the effect of $\mathrm{N}$ and $\mathrm{K}$ fertilization on eggplants, a study on the occurrence of $C$. cyathicollis was developed. Experimental treatments consisted of $3 \times 3 \times 3$ factorial, with four repetitions. Three nitrogen levels $(0,60$ and $120 \mathrm{~kg} / \mathrm{ha})$ and three potassium levels $(0,30$ and $60 \mathrm{~kg} / \mathrm{ha}$ ) were used. Weekly samplings were carried out during three periods of the day (morning, afternoon and night). The results indicated significant statistical differences in the numbers of insects of the species $C$. cyathicollis between the plants that had been fertilized with $120 \mathrm{~kg}$ of N/ha (224.42) and those that had been fertilized with $60 \mathrm{~kg}$ of $\mathrm{N} / \mathrm{ha}$ (197.50) in the afternoon.

Key words: Tingidae, period of the day, nitrogen, potassium 


\section{Introdução}

Existem, atualmente, diversos estudos correlacionando a deficiência e/ou excesso de um determinado nutriente e sua influência na infestação de determinadas pragas e doenças. Em geral, esses estudos evidenciam que uma fonte de nutriente equilibrada assegura o crescimento ótimo da planta e sua resistência.

Os efeitos indiretos das práticas de adubação agem através das mudanças na composição de nutrientes das plantas hospedeiras e influenciam na resistência das mesmas ao ataque de muitas pragas. Entre os fatores nutricionais que influenciam os níveis de danos de artrópodes em uma cultura, o nitrogênio total tem sido considerado crítico para ambos, plantas e predadores (Scriber, 1984; Slansky e Rodriguez, 1987).

Segundo Herzog e Funderburk (1986) e Schulze e Djuniadi (1998), a fertilidade do solo influencia diretamente o desenvolvimento de plantas podendo afetar indiretamente a densidade populacional de insetos fitófagos. Estudos envolvendo relações entre adubação de plantas e incidências de insetos podem indicar a quantidade em que um nutriente poderá favorecer ou não a ocorrência desses insetos nas culturas. Assim, o status nutricional das plantas pode afetar os insetos fitófagos através da produção diferencial de metabólitos secundários.

De acordo com Tingey e Singh (1980), variações quantitativas e qualitativas em fatores ambientais, exercem influência no crescimento e no desenvolvimento das plantas, que geralmente, conduzem a alterações na adequação nutricional de tecidos da planta a artrópodos fitófagos.

O nitrogênio e o potássio são nutrientes essenciais, de uma maneira geral, alguns pesquisadores acreditam que o excesso de nitrogênio provoca um aumento na suscetibilidade das plantas ao ataque de pragas e doenças, enquanto que o de potássio diminui. A nutrição adequada com o potássio favorece a síntese de proteínas e reduz o acúmulo de carboidratos e compostos solúveis de nitrogênio nas células, situação esta que favorece diversas espécies de insetos e ácaros (Beringer e Trolldenier, 1979).
Caixeta et al. (2004), estudando a correlação entre a nutrição do cafeeiro e o bicho mineiro, testaram tratamentos formados pela combinação das doses de nitrogênio $\left(3,7,11\right.$ e $\left.15 \mathrm{mmol} \mathrm{L}^{-1}\right)$, sendo $20 \%$ do nitrogênio na forma de $\mathrm{NH}^{+4}$, com as doses de potássio $(3,5,7 \mathrm{e}$ $9 \mathrm{mmol} \mathrm{L}^{-1}$ ), e concluíram que as mudas de cafeeiro com nutrição nitrogenada adequada e mais vigorosas foram mais atacadas pelo inseto.

Pesquisando plantas de couve-de-bruxelas (Brassica oleracea L. var. gemmifera), suplementadas com altas taxas de nitrogênio e potássio, Endem (1966) observou que houve uma influência na reprodução de afídeos e concluiu que o aumento teores de nitrogênio e o decréscimo nos teores de potássio proporcionaram aumento nas taxas de fecundidade e reprodução desse inseto.

Bortoli et al. (2005), estudando os aspectos biológicos e danos de Diatraea saccharalis, concluíram que de um modo geral, as doses mais equilibradas de nitrogênio tendem a promover um bom desenvolvimento para as larvas de $D$. saccharalis, sendo que as menores porcentagens de dano foram verificadas nas menores doses de N (100, 200 e 400 ppm); enquanto que o potássio, quanto maior a dose, apesar de favorecer o desenvolvimento das lagartas, tornam as plantas menos danificadas pelo inseto.

De acordo com Vanetti (1982) e Castro et al. (2004), o inseto, conhecido como percevejo-manchador, é encontrado em solanáceas cultivadas e silvestres, sendo considerado importante praga na região da baixada fluminense do Rio de Janeiro. E, segundo Kogan (1960) a berinjela é mais suscetível à Corythaica cyathicollis que outras solanáceas (tomateiro e batatinha), que se apresentaram quase isentas do inseto. Afirmou que, as culturas não-tratadas são altamente prejudicadas; quando não havia destruição total das plantas, havia uma queda acentuada na produção e as plantas de berinjela ficavam enfraquecidas pelo ataque do inseto, ocorrendo doenças fúngicas e viroses.

A berinjela é exigente em nutrientes, principalmente nitrogênio e potássio. A época do plantio da cultura (setembro a fevereiro), coincide com o pico populacional de C. cyathicollis (Filgueira, 2000; Filgueira, 2003; Conceição et al., 1999). Deste modo, a relação entre as quantidades de nitrogênio e potássio fornecidas às plantas de Solanum melongena poderão conferir 
maior tolerância ou susceptibilidade ao inseto. Diante dos fatos, o presente trabalho objetivou-se estudar a influência das interações das doses de nitrogênio e potássio sobre a quantidade de insetos da espécie C. cyathicollis a partir de amostragens diurnas e noturnas. Além de determinar a porcentagem dos macronutrientes $(\mathrm{Ne}$ $\mathrm{K})$ e a porcentagem de danos causados pelo inseto nas folhas das plantas de Solanum melongena.

\section{Material e Métodos}

O experimento foi conduzido no campo experimental da UFRRJ, entre os meses de setembro/2004 a janeiro/2005, em uma área total de $1031,10 \mathrm{~m}^{2}$. A região em questão está localizada a $22^{\circ} 45^{\prime} \mathrm{S}$ e $43^{\circ} 41^{\prime} \mathrm{W}$, apresenta inverno seco com temperaturas amenas e verão chuvoso com temperaturas elevadas, sendo a taxa de precipitação média anual em torno de $1200 \mathrm{~mm}$.

As plantas de $S$. melongena receberam três níveis de adubação nitrogenada $\left(0,60,120 \mathrm{~kg} \mathrm{ha}^{-1}\right)$ e três níveis de adubação potássica $\left(0,30,60 \mathrm{~kg} \mathrm{ha}^{-1}\right)$. Utilizouse uréia e cloreto de potássio, como fontes de nitrogênio e potássio, respectivamente Aplicou-se fósforo, em dose única $90 \mathrm{~kg} \mathrm{ha}^{-1}$ de $\mathrm{P}_{2} \mathrm{O}_{5}$, antes do transplante, utilizando como fonte o superfosfato simples.

Para o monitoramento dos insetos, utilizou-se o delineamento fatorial, sendo os tratamentos dispostos em esquema fatorial $2 \times 3 \times 3$ (nutrientes, doses, períodos do dia), com quatro repetições. As inspeções na área experimental foram realizadas no período de florescimento e frutificação, uma vez por semana, nos três períodos do dia (manhã, tarde e noite). Procurouse investigar o período de maior incidência de insetos. Foram realizadas 12 visitas. As coletas foram realizadas através de catação manual e do uso da rede entomológica. $\mathrm{O}$ tempo de permanência no campo em cada parcela ficou estabelecido em dez minutos, nas duas plantas centrais de cada parcela. Os insetos coletados foram armazenados em frascos contendo álcool $70 \%$, etiquetado com a identificação da parcela, data e período do dia. Os materiais coletados foram imediatamente triados, identificando-se e quantificando-se os insetos mais freqüentes. Deu-se ênfase ao estudo da $C$. cyathicollis, por ser praga de interesse da cultura na região.
Os dados foram submetidos à análise de variância, pelo teste F, por intermédio do software Sisvar ${ }^{\circledR}$ - versão 4.3 (Ferreira, 2000), sem sofrer transformações. Para as características significativas, aplicou-se o teste de Tukey para a comparação entre as médias dos tratamentos.

\section{Resultados}

As médias da temperatura, umidade relativa do ar e precipitação durante o período de monitoramento de insetos, foram de $25,83^{\circ} \mathrm{C}, 58,87 \%, 116,73 \mathrm{~mm}$, respectivamente.

Em relação ao estudo da $C$. cyathicollis, não foi observada diferença significativa entre os tratamentos, quando avaliado isoladamente, mas houve uma interação entre as doses de nitrogênio e o período do dia. Observou-se uma diferença estatística significativa no número de insetos da espécie quando as plantas foram adubadas com $0 \mathrm{~kg}$ de N/ha (229) e 60kg de N/ha (197), no período do tarde.

De acordo com as médias obtidas, a dosagem de $60 \mathrm{~kg}$ de N/ha e o período da tarde colaboram para uma maior incidência de insetos. Quanto ao potássio, não foram verificadas diferenças estatísticas significativas quando se utilizou esse elemento químico (Tabelas 1 e 2).

TABELA 1: Resumo da análise de variância para densidade populacional média de $C$. cyathicollis presentes em plantas de S. melongena cultivadas em diferentes doses de nitrogênio potássio, em diferentes períodos do dia (manhã, tarde, noite). Seropédica, RJ, $2005(\mathrm{~N}=12)$.

\begin{tabular}{lll}
\hline \multicolumn{1}{c}{ Fontes de variação } & GL & Quadrado Médio $^{(\mathbf{1})}$ \\
\hline Nitrogênio $(\mathrm{N})$ & 2 & $4306,43 \mathrm{~ns}$ \\
\hline Potássio $(\mathrm{K})$ & 2 & $8821,66 \mathrm{~ns}$ \\
\hline Período do dia & 2 & $19631,73^{* *}$ \\
\hline Bloco & 3 & $10077,20 \mathrm{~ns}$ \\
\hline $\mathrm{N}$ x K & 4 & $5100,14 \mathrm{~ns}$ \\
\hline $\mathrm{N}$ x Período do dia & 4 & $8250,33^{*}$ \\
\hline K x Período do dia & 4 & $5618,09 \mathrm{~ns}$ \\
\hline N x K x Período do dia & 8 & $3426,74 \mathrm{~ns}$ \\
\hline erro & 78 & 3050,41 \\
\hline CV $(\%)$ & 28,39 & \\
\hline
\end{tabular}

$(1)^{* *}$ significativa a $1 \%,{ }^{*}$ significativa a $5 \%$ e ns = não significativo. 
TABELA 2: Número médio de insetos de C. cyathicollis (Costa, 1864) em plantas de S. melongena adubadas com nitrogênio. Seropédica, $\mathrm{RJ}(\mathrm{N}=12)$.

\begin{tabular}{ccccc}
\hline \multirow{2}{*}{ Período } & \multicolumn{4}{c}{ Nitrogênio (Kg/ha) } \\
\cline { 2 - 5 } & $\mathbf{0}$ & $\mathbf{6 0}$ & $\mathbf{1 2 0}$ & Média \\
\cline { 2 - 5 } & $173 \mathrm{a}$ & $223 \mathrm{a}$ & $191 \mathrm{a}$ & 196 \\
\hline Manhã & $229 \mathrm{a}$ & $197 \mathrm{~b}$ & $224 \mathrm{ab}$ & 217 \\
\hline Tarde & $167 \mathrm{a}$ & $199 \mathrm{a}$ & $143 \mathrm{a}$ & 170 \\
\hline Noite & 190 & 207 & 186 & \\
\hline Média & &
\end{tabular}

Médias seguidas pela mesma letra, em linhas, não diferem entre si pelo teste de Tukey $(\mathrm{p} \leq 0,05)$.

\section{Discussão}

De acordo com os resultados obtidos, o balanço nutricional de nitrogênio assim como o período do dia poderão influenciar na população de $C$. cyathicollis em S. melongena. Pois, de acordo com Lara (1992), as concentrações dos nutrientes minerais influenciam na vulnerabilidade e resistência de insetos, e estes tendem a preferir aquelas plantas que lhes forneçam alimentos nutricionalmente favoráveis.

Segundo Herzog e Funderburk (1986), o uso de adubação pode interferir no crescimento das culturas, alterar os níveis de nutrientes em diferentes partes da planta e conseqüentemente, agir de modo diferente sobre populações de insetos. Em tangerina poncã, Ramalho-Silva et al. (1998) observaram que adubação nitrogenada e potássica na população de Phyllocnistis citrella (Lepidoptera, Gracilariidae) não influenciaram na população do inseto, e concluíram que talvez o efeito seja na fenologia da planta, induzindo a brotação, e conseqüentemente à incidência do inseto.

Quanto ao potássio, não foram observadas influências desse elemento na incidência de $C$. cyathicollis. Resultados semelhantes foram encontrados por Feltrin et al. (2002) avaliando o efeito de fontes de potássio na infestação de Bemisia tabaci em tomateiros, observaram que as diferentes fontes de potássio $\left(\mathrm{KCl}+\mathrm{K}_{2} \mathrm{SO}_{4}\right.$ $+\mathrm{K}_{2} \mathrm{SiO}_{3} ; \mathrm{KCl}+\mathrm{K}_{2} \mathrm{SO}_{4} ; \mathrm{K}_{2} \mathrm{SO}_{4} ; \mathrm{KCl}$ ), não influenciaram a infestação na ocorrência do inseto-praga, porém Rodrigues e Cassino (2003), avaliando os efeitos da adubação potássica sobre a população de $A$. floccosus em laranja doce (cv folha murcha), observaram que a adição de potássio na adubação da planta diminui a população do aleurodídeo.

Estudando os efeitos da adubação potássica em tomateiros sobre Bemisia tabaci em ambiente protegido, Feltrin et al. (2002) observaram que o potássio não influenciou na oviposição e no número de ninfas do inseto, considerando três épocas de avaliações. Porém, constataram um aumento significativo na quantidade de imaturos nos folíolos das plantas na terceira época de avaliação.

Embora, as plantas que receberam a dosagem de $60 \mathrm{~kg} / \mathrm{ha}$ serem pouco atacadas no período da tarde, observou-se que em média foram as mais atacadas. Esses resultados demonstram que a adubação com nitrogênio poderá tornar as plantas de $S$. melongena mais susceptíveis ao ataque de $C$. cyathicollis, uma vez que, a analisando estatisticamente, as plantas adubadas foram igualmente atacadas que plantas não adubadas.

Foi observado que a diminuição de temperatura no decorrer do dia diminui a incidência de C. cyathicollis em plantas de $S$. melongena, adubadas com nitrogênio.

\section{Agradecimentos}

À FAPERJ pela concessão da bolsa de estudos. Ao curso pós-graduação em Fitotecnia da UFRRJ. Aos colaboradores do laboratório de entomologia florestal da UFRRJ.

\section{Referências}

Beringer, H.; Troodenier G. 1979. Influence of potassium nutrition on the response to environmental stress. 1979. Proceeding of the Congress Potassium Research-Review and Trends, Bern, Switzerland, p.189-222.

Bortoli, S. A.; Dória, H. O. S.; Albergaria, W. M. M. S.; Botti, M. V. 2005. Aspectos biológicos e dano de Diatraea saccharalis (Fabr., 1794) (Lepidoptera: Pyralidae) em sorgo cultivado sob diferentes doses de nitrogênio e potássio. Ciência Agrotécnica, 29 (2): $267-$ 273.

Caixeta, S. L; Martinez, H. E. P.; Picanço, M. C.; Cecon, P. R.; Esposti, M. D. D.; Amaral, J. F. T. 2004. Nutrição e vigor de mudas 
de cafeeiro e infestação por bicho mineiro. Ciência Rural, 34 (5): 1429-1423.

Castro, C. M.; Alves, B. J. R.; Almeida, D. L.; Ribeiro, R. L. D. 2004. Adubação verde como fonte de nitrogênio para a cultura da berinjela em sistema orgânico. Pesquisa Agropecuária Brasileira, 39 (8): 123-125.

Conceição. J. C.; Rangel, F. W.; Santos, W. S. ; Menezes, E. B. ; Akiba, F. G. 1999. Verificação de patogenecidade de isolado bacteriano de Corythaica cyathicollis (Hemiptera, Tingidae) Anais da

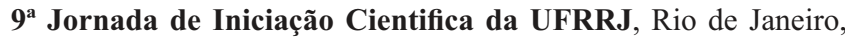
Brasil, p.509.

Endem, H. F. van. 1966. Studies on the relations of insect and host plant. III A comparison of the reproduction of Brevicoryne brassicae and Myzus persicae (Hemiptera: Aphididae) on brussels sprout plants suplied with different rates of nitrogen and potassium. Entomologia Experimentalis et Applicata, 9 (4): 444-460.

Feltrin; D. M.; Lourenção, A. L.; Furlani, P. R.; Limonta, C. R. 2002. Efeito de fontes de potássio na infestação de Bemisia tabaci biótipo $\mathrm{B}$ e nas características de frutos de tomateiro sob ambiente protegido. Campinas: Bragantia, 61 (1): 49-57.

Ferreira, D. F. 2000. Análises estatísticas por meio do Sisvar para Windows versão 4.0. Anais da Reunião Anual da Região Brasileira da Sociedade Internacional de Biometria, São Paulo, Brasil, p.255-258.

Filgueira, F. A. R. 2000. Novo manual de olericultura: agrotecnologia moderna na produção e comercialização de hortaliças. Editora UFV, Viçosa, Brasil, 402pp.

Filgueira, F. A. R. 2003. Novo manual de olericultura: agrotecnologia moderna na produção e comercialização de hortaliças. Editora UFV, Viçosa, Brasil, 359pp.
Herzog, D. C.; Funderburk, J. E. 1986. Ecological bases for habitat management and cultural control. In: Kogan, M. (Ed.). Ecological theory and integrated pest management practice. Wiley Interscience, New York, USA, p.217-259.

Kogan, M. 1960. Corythaica cyathicollis (Costa, 1864) (Hemiptera, Tingidae) Aspectos sistemáticos, biológicos e econômicos. Memórias do Instituto Oswaldo Cruz, 58 (1): 59-88.

Lara, F. M. 1992. Princípios de entomologia. $3^{\mathrm{a}} \mathrm{ed}$. Editora Ícone, São Paulo, Brasil, 331 p.

Ramalho-Silva, P. R.; Rodrigues, W. C.; Santos, W. C.; Cassino, P. C. R.; Pinto, J. M. 1998. Influência da adubação nitrogenada e potássica sobre a população de $P$. citrella (Lep., Gracilariidae) em tangerina Poncã. Anais XVII Congresso Brasileiro de Entomologia, Rio de Janeiro, Brasil, p. 494

Rodrigues, W. C.; Cassino, P. C. R. 2003. Efeitos da adubação nitrogenada e potássica sobre a população de $A$. floccosus (Homoptera, Aleyrodidae) em laranja doce (Citrus sinensis) cv folha murcha. Revista Universidade Rural, 22 (1): 55-59.

Schulze, W.; Djuniadi, D. 1998 Introduction of integrated pest management in rice cultivation in Indonesia. Pflanzen Nachrichten, 2 (1): 97-105.

Scriber, J. M. 1984. Host plant suitability. In: Bell, W. \& Carde, R. (eds). Chemical ecology of insects. Chapman and Hall, London, UK, p.159-202.

Slansky, F.; Rodriguez, J. G. 1987. Nutritional ecology of insects, mites, spiders and related invertebrates. Wiley, New York, USA, 69pp.

Tingey, W. M.; Singh, S. R. 1980. Environmental factors influencing the magnitude and expression of resistance. In: Maxwell, F. G. \& Jennings, P. R. (Ed.). Breeding plant resistant to insects. John Wiley and Sons, New York, USA, p.87-114. 